\title{
Cold Gas Sprayed Stellite-6 Coatings and their Wear Resistance
}

\section{Cinca $\mathrm{N}^{*}$ and Guilemany JM}

Centre de ProjeccióTèrmica (CPT). Universitat de Barcelona, Martí i Franquès 1, E-08028, Barcelona, Spain

\begin{abstract}
Here we report on the successful deposition of stellite-6 coatings by Cold Gas Spray (CGS) technology and their tribological properties in correlation with the as-sprayed structure. The deposits were dense and showed satisfactory interparticle bonding. The deformation mechanisms involved within the process are evaluated with regard to the particle shape and dendritic deformation at the boundaries and also internal structural defects.

Despite the lower hardness of CGS coatings compared to HVOF ones, they displayed relatively good wear rates under both abrasive and sliding conditions. The wear mechanisms are discussed mainly in terms of local oxidation and possible martensitic phase transformation of stellite.
\end{abstract}

Keywords: Co-based alloy; Coating; Coatings; Wear resistant; Wear mechanisms; TEM

\section{Introduction}

Industrial machinery is affected by inevitable corrosion and/or wear. Given the expense of replacing equipment parts, most companies prefer to repair damaged pieces, and many studies have therefore addressed this issue [1]. Repair is a much more economical alternative to improve the service life of components, and the technologies applied for this purpose include laser coating and thermal spraying [2]. Laser cladding allows the use of an additional protective gas flow to minimize oxidation; however, there may be a small Heat-Affected Zone (HAZ), such as that caused by welding, and the substrate surface structure may be affected by superficial melting. In contrast, there is no HAZ associated with thermal spray technology. Thermal spraying of oxygensensitive materials can be achieved by vacuum plasma spraying, but this requires large investments. In addition, thermal stresses are introduced in both processes. An alternative, Cold Gas Spraying (CGS), allows the deposition of oxygen-sensitive and heat-sensitive materials in the solid state and most stresses are compressive[3]. The main difference between CGS and conventional thermal spraying is that the former is based on the plastic deformation of feedstock on impact with the substrate, and no melting is produced. The method has recently been patented for wear-resistant and corrosion-resistant alloys [4,5]. The first patent deals with aluminum-containing materials, which can be used to effect repairs involving pure aluminum, aluminum alloy 6061, which contains magnesium and silicon, aluminum alloy 2219, Al-12Si alloy, Al-Sc alloy, and aluminum alloy 6061/B4C; the second patent concerns the use of Stellite694 and Tribaloy800 as coating materials.

The feasibility of particle bonding depends mainly on particles reaching the so-called critical velocity values, which are influenced by the mechanical and physical properties of the sprayed material as well as the size, distribution and morphology of the particles. Schmidt et al. developed equations to find the critical velocity [6]:

$$
v_{\text {crit }}=\sqrt{A \frac{\sigma}{\rho}+B C_{P}\left(T_{m}-T_{r}\right)}
$$

where $\sigma$ is the temperature-dependent flow stress, $\rho$ is the density, $\mathrm{C}_{\mathrm{p}}$ is the heat capacity, $T_{m}$ is the melting temperature, $T_{r}$ is the mean temperature of particles upon impact, and $A$ and $B$ are fitting constants.

The present paper further explores the properties of Stellite-6 CGS coatings for wear protection. In general, cobalt-based alloys show outstanding resistance to oxidation and to various forms of wear up to temperatures close to their melting point. As a result of these features, these alloys are commonly used in critical parts for the chemical processing, oil and gas, and power industries [7].Co/Cr alloys exhibit excellent anti-galling properties under high-load sliding conditions. It is known that the $\mathrm{fcc}(\gamma)$ stellite phase transforms to the Hexagonally Close-Packed(HCP) phase $(\varepsilon)$ at a certain stress level as result of a martensitic transformation, which occurs by shear rather than by cooling below the transformation temperature at $690 \mathrm{~K} \mathrm{[8].}$

However, a high level of friction occurs under low contact pressures. The aim of this work is twofold: examine the appearance of the HCP phase when the material is affected by wear damage and study its influence on wear rate.

\section{Experimental Procedure}

The Stellite powder used as feedstock was Diamalloy 4060NS from the SULZER Company and it was obtained by an atomization process. It was deposited onto low alloy carbon steel G41350 UNS coupons that were previously degreased and ground.

The Cold Gas Spray (CGS) equipment was a KINETICS 4000 (Cold Gas Technology, Ampfing, Germany). In order to build deposits as dense as possible, the spraying conditions were optimized from previous studies and were as follows: gas temperature and pressure (nitrogen) $800^{\circ} \mathrm{C}$ and 38 bar respectively, $20 \mathrm{~mm}$ of spraying distance and $250 \mathrm{~mm} / \mathrm{s}$ traverse gun speed.

The feedstock and cross-sections were examined by Optical and Scanning Electron Microscopy. The coating microstructure was revealed by etching with a mixture of acids $\left(15 \mathrm{ml} \mathrm{HNO}_{3}, 15 \mathrm{ml} \mathrm{CH}_{3} \mathrm{COOH}\right.$, $60 \mathrm{ml} \mathrm{HCl}$ and $20 \mathrm{ml}$ of $\mathrm{H}_{2} \mathrm{O}$ ). In addition, X-Ray Diffraction (XRD) was used to characterize the phases present and to assess the degree

*Corresponding author: Cinca N,Centre de ProjeccióTèrmica (CPT). Universitat de Barcelona, Martí i Franquès 1, E-08028, Barcelona, Spain, Tel: +34934021302; E-mail: ncinca@cptub.eu

Received December 13, 2012; Accepted January 09, 2013; Published January 16,2013

Citation: Cinca N, Guilemany JM (2013) Cold Gas Sprayed Stellite-6 Coatings andtheir Wear Resistance. J Material Sci Eng 2: 122. doi:10.4172/21690022.1000122

Copyright: ( 2013 Cinca N, et al. This is an open-access article distributed unde the terms of the Creative Commons Attribution License, which permits unrestricted use, distribution, and reproduction in any medium, provided the original author and source are credited. 
of order in the feedstock powders and as-sprayed coatings. All X-ray measurements were done on a Bragg-Brentano $\theta / 2 \theta$ Siemens D-500 diffractometer with $\mathrm{Cu} \mathrm{Ka}$ radiation.

The microhardness of the as-sprayed coatings and the oxidized coatings were studied using a Vickers indentation tester MATSUZAWA MXT-a at a load of $200 \mathrm{gf}$ for $15 \mathrm{~s}$ in the cross-sections. On average, at least 20 indentations were performed.

Following ASTM G65-00, the Rubber Wheel test consisted of a rubber wheel rotating at a constant speed of $139 \mathrm{rpm}$ on the specimen while silica particles (between 0.4 and $0.8 \mathrm{~mm}$ ) flowed by gravity between the two contacting surfaces. The samples were tested in their as-sprayed state.

A normal load of $50 \mathrm{~N}$ was applied and the mass loss was measured up to $30 \mathrm{~min}$. The abrasion wear rate $W$ was calculated from the average mass loss as $\mathrm{mm}^{3} \mathrm{~N}^{-1} \mathrm{~m}^{-1}[9]$.

Friction tests were carried out with a ball-on-disc system following ASTM G99-03, where an 11-mm diameter WC-6Co ball was used to cause friction against the polished coating surface (below $0.8 \mathrm{Ra}$ ). During the test, the temperature (around $25^{\circ} \mathrm{C}$ ) and humidity (below $20 \%)$ were controlled in the closed chamber where the experiments were performed. A sliding speed of $0.11 \mathrm{~m} / \mathrm{s}$, track diameter of $14 \mathrm{~mm}$ and sliding distance of $1000 \mathrm{~m}$ were kept constant for all the tests. The variation in friction coefficient (FC) with sliding distance was registered at 5,10 and $15 \mathrm{~N}$ for the coatings. According to the standard, the FC is given as the average of the values obtained for the last $200 \mathrm{~m}$.

The wear rate $K\left(\mathrm{~mm}^{3} \mathrm{~N}^{-1} \mathrm{~m}^{-1}\right)$ was calculated from the volume loss in the wear track [8], which was calculated by means of confocal microscopy using a Dual Core 3D Measuring microscope DCM 3D.

\section{Results and Discussion}

\section{Feedstock characterization}

The feedstock was an atomized stellite- 6 powder with a particle size distribution of $-45+15 \mu \mathrm{m}$ (Figure 1a). A Quanta 200 FEI, XTE 325/ D8395 electron microscope operating at $20 \mathrm{kV}$ and with a step size of $0.40 \mu \mathrm{m}$ was used to examine the grain structure of the feedstock. In the Euler angle maps presented, each point is colored on the basis of crystal orientation, with red corresponding to the $\left(\begin{array}{lll}0 & 0 & 1\end{array}\right)$ direction, blue to (1 1 $1)$ and green to $\left(\begin{array}{lll}1 & 0 & 1\end{array}\right)$. High-angle boundaries $\left(\mathrm{HABs}>15^{\circ}\right)$ are shown by black lines, while low-angle boundaries $\left(\mathrm{LABs},<15^{\circ}\right)$ are depicted by white lines. A relatively good resolution is seen in the pattern quality map (Figure 1b). The Euler angle map shows typical dendrites, with a micrometer size and their respective orientations with low defect density and lattice strain (Figure 1c).

\section{Microstructural characterization}

The CGS coating optimized following the spraying conditions used in previous studies is shown in Figure 2a [10]. A high compacity was obtained. The HVOF technique has also been used to generate stellite- 6 coatings with noticeable structural differences, depending on the type and flux of fuel gases; the spraying conditions are presented in table 1 [11]. Whenever hydrogen or propylene is used, the feedstock melts and intersplat oxidation is visible. The "hot" (propylene) conditions and those sprayed with hydrogen lead to more melted splats. They are highly deformed and do not show the initial dendritic particle structure. The less energetic conditions, those labelled as "cold" present a high proportion of non-deformed splats. In between, the "fast" conditions show a mixture of the previous morphologies.

Comparatively, the lower temperature and higher kinetic energy in CGS prevents oxidation and reduces the porosity content (approximately the difference is $0.33 \pm 0.01$ vs. $2 \pm 0.4 \%$ ).

Figure $2 b$ and $c$ show the etched coating; the particle boundary network is revealed in figure $3 \mathrm{~b}$. The particles in the coating maintain their round shape, which is indicative of their resistance to deformation. Compared to other Face Centered Cubic (FCC) metals, such as nickel and aluminum, which despite their different properties exhibit similar critical velocities [6], stellite-6 has a similar density to that of nickel $\left(\left(8.46 \mathrm{~g} / \mathrm{cm}^{3}\right.\right.$ and $8.89 \mathrm{~g} / \mathrm{cm}^{3}$ respectively), a slightly higher melting temperature $\left(1558-1658^{\circ} \mathrm{C}\right.$ and $1453^{\circ} \mathrm{C}$ respectively) and analogous heat capacity i.e $421 \mathrm{~J} / \mathrm{kgK}$ for pure cobalt compared to $456 \mathrm{~J} / \mathrm{kgK}$ for

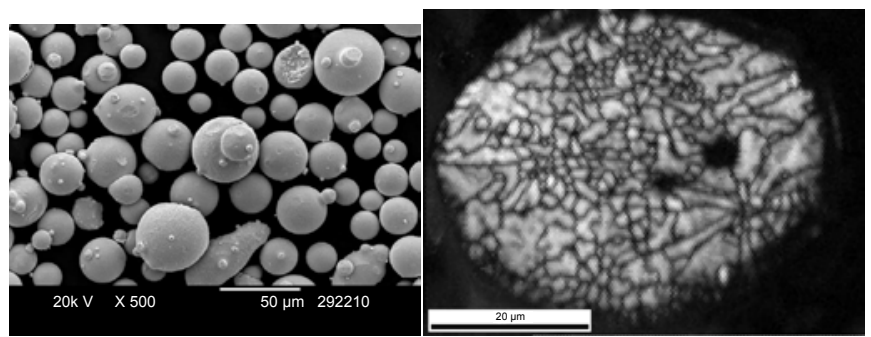

(a)

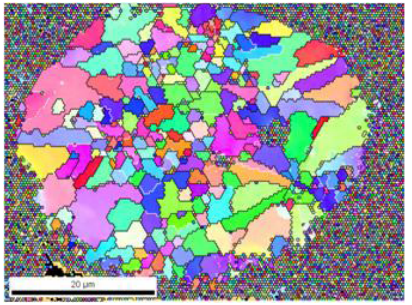

Figure 1: (a) Surface morphology of the feedstock, (b) pattern quality map and (c) Euler angle map of the cross-sections of stellite powders

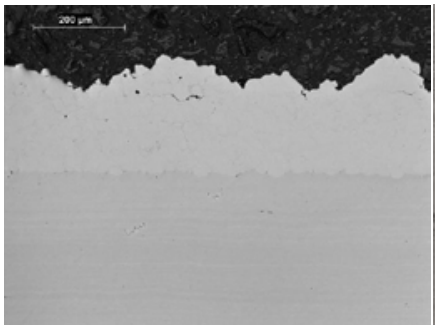

(a)

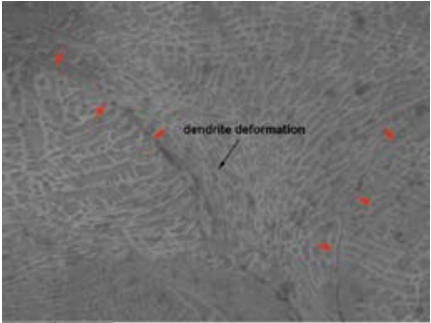

(c)

Figure 2: (a) Optical cross section of the optimized coating, (b) Normarsky image of the etched coating and (c) SEM features of interparticle boundaries (red arrows indicate particle boundaries). 


\begin{tabular}{|c|c|c|c|c|}
\hline & \multicolumn{3}{|c|}{ PROPYLENE } & \multirow{2}{*}{ HYDROGEN } \\
\hline & HOT & COLD & FAST & \\
\hline Oxygen flow rate (I/min) & 341 & 189 & 253 & 214 \\
\hline Fuel flow rate (I/min) & 77 & 87 & 77 & 738 \\
\hline Carrier gas (I/min) & 341 & 189 & 253 & 344 \\
\hline Spraying distance (mm) & \multicolumn{3}{|c|}{250} \\
\hline
\end{tabular}

Table 1: HVOF thermal spray parameters of stellite-6.

nickel. The major difference is the temperature-dependent flow stress, which depends directly on the ultimate strength [10]; $\sigma_{\text {ultimate }}$ of stellite corresponds to $690 \mathrm{MPa}$, a value higher than that of nickel. Therefore according to equation 1 , stellite leads to expected higher critical velocities. Figure $2 \mathrm{c}$ shows some features of the dendrite deformation at the particle boundaries.

The deposition mechanisms involve mechanical deformation of both the sprayed particle and the substrate at high strain rates (up to $10^{6}-10^{9} \mathrm{~s}^{-1}$ ), particularly at the impact interface. The subsequent strain accommodation from deformation can be produced either by twinning, dislocation slip, displacive transformation or diffusional creep processes [12]. Cobalt has a martensitic phase transformation, which can be induced by temperature, and it occurs by cooling at about $690 \mathrm{~K}$ from its high temperature (FCC) to low temperature (HCP) phase, or by plastic deformation through a shear-activated mechanism. Since the alloying elements in the stellite- 6 alloy strongly stabilize the FCC structure, we studied whether the plastic deformation of the particle during impact induces the appearance of the HCP phase; however, the $\mathrm{X}$-ray spectra indicated the presence of only the cubic phase. Therefore, the only mechanisms involved were twinning or dislocation motion. A close examination by means of Transmission Electron Microscopy revealed the presence of a large number of twins in the coating (Figure 3 ); the observation that these were parallel indicates that they were caused by deformation rather than annealing during a posterior migrational recrystallization. This conclusion is consistent with the Stacking Fault Energy (SFE) values corresponding to these alloys. The SFE determines the dominant deformation mechanism (Figure 4) [13]. Pure cobalt, with an HCP crystal structure, has a very low SFE $(27 \pm$ $4 \mathrm{~mJ} . \mathrm{m}^{-2}$ ) [14], and for Co-based alloys, SFE extends to between 10$50 \mathrm{~mJ} \cdot \mathrm{m}^{-2}$ [15]. Given that the threshold pressure for the initiation of twinning for FCC metals is a function of SFE [16], the lower the SFE, the easier twin formation will be. In accordance with these statements and according to figure 4 , twinning is the most suitable mechanism.

Observation of the coating highlighted other highly deformed regions (Figure 5a), whose electron diffraction pattern showedtexturization (Figure $5 \mathrm{~b}$ ). Figure $5 \mathrm{c}$ shows a grain boundary with polycrystalline regions at both sides of the interface, as indicated by the electron diffraction patterns (Figure $5 \mathrm{~d}$ and $5 \mathrm{e}$ ). Such patterns reveal misorientation of these crystallites. This feature may be associated with a non-recrystallization phenomenon, as it is normally detected in CGS near the interfaces where the so-called Adiabatic Shear Instabilities (ASIs) occur. Similar electron difraction patterns were observed by $\mathrm{Wu}$ et al. [17] in refined grains after mechanical attrition.

ASIs are produced by shear strain and local dominance of thermal softening over strain hardening; the heat dissipation makes the temperature rise above approximately $0.5 \mathrm{~T}$ and recrystallization takes place. It is then assumed that, upon particle impact with the surface, the temperature at the interface is not high enough and grain refinement is associated with a transition of strain accommodation from twinning to dislocation slip with increasing strain, the dislocation boundaries showing a high angle when their misorientations are increased.

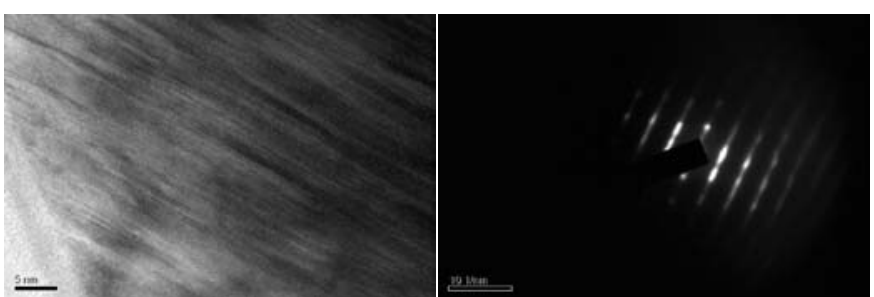

Figure 3: Fine twins and the corresponding SAED pattern within the stellite-6 coating.

Bundles of

hcp and twins

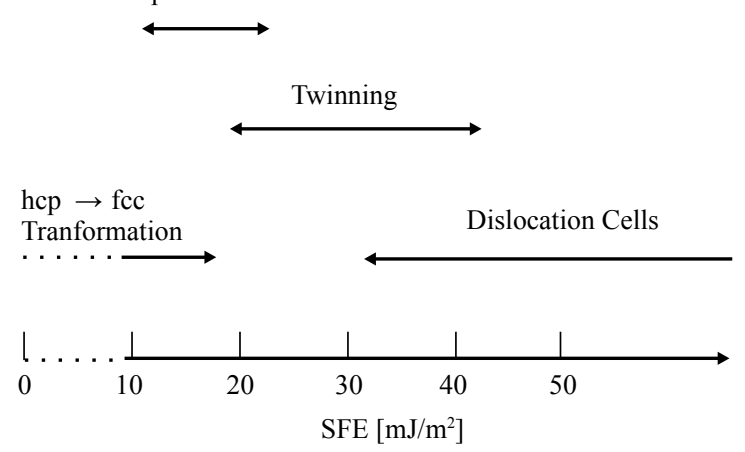

Figure 4: Deformation structures observed near room temperature as a function of stacking fault energy [13].

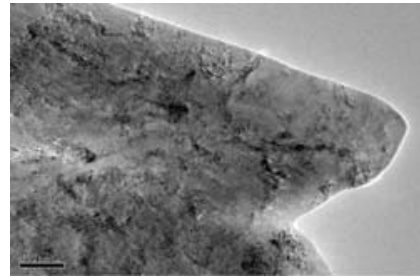

a

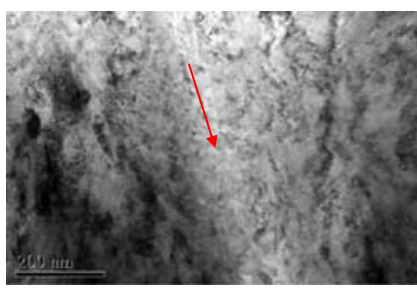

c

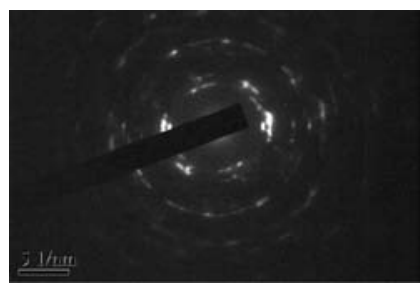

Figure 5: $(a, c)$ Polycrystalline deformed region and particle boundary; (b) SAED pattern of Figure "a" and, (d, e) SAED pattern of the left and right sides of Figure "c".

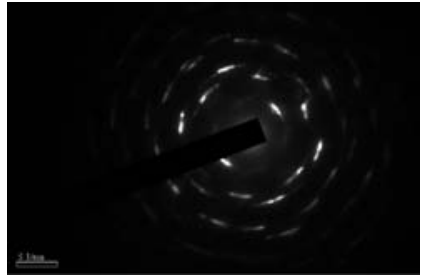

b

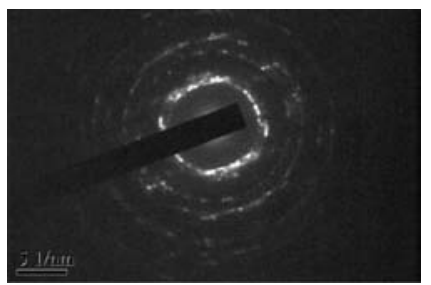

d 


\section{Tribology performance}

Abrasive wear behavior is generally related to material hardness according to the Archard equation [18]. Stellitehardness values are normally in the range of $350 \mathrm{HV}$ and $600 \mathrm{HV}$ and are dependent on the capacity of the $\mathrm{C}$ content to form carbides as well as on the dendrite size; the finer the microstructure, the harder the material. The feedstock powder obtained by atomization had a mean hardness value of $355 \pm$ $96 \mathrm{HV}$, whereas the final CGS coating registered $682 \pm 30 \mathrm{HV}$, thus indicating that the material underwent strain hardening.

However, the abrasive wear resistance for the CGS stellite- 6 coatings was $1.88 \times 10^{-4} \pm 3.5 \times 10^{-5} \mathrm{~mm}^{3} / \mathrm{Nm}$ (mass loss of $7.43 \times 10^{-3} \mathrm{~g} / \mathrm{min}$ ) compared to the $7.0-8.0 \times 10^{-4} \mathrm{~mm}^{3} / \mathrm{Nm}$ obtained for the harder HVOF coatings [19]; our results, which contradict the Archard equation, must therefore be interpreted with care, since oxidation, porosity and carbide distribution may be relevant when considering coating structures. In the case of laser cladding coatings, dilution plays a key role and some authors found these coatings to exhibit lower abrasive resistance than the stainless steel substrates due to their lower fracture toughness, while reporting that microcutting and microcracking are the most likely wear mechanisms when stellite hardness increases [19]. Figure 6 shows the micrograph of the damaged surface; the scars might indicate a microcutting mechanism while the roughness observed could be attributed to microploughing.

Of note, XRD of the abraded area revealed the presence of the HCP phase (Figure 7), thereby suggesting that the martensitic transformation is also involved. Under sliding conditions, stellite alloys exhibit excellent anti-galling properties under high-load sliding conditions, which is the reason why they were originally introduced as materials for sealing the surfaces of gate valves [20,21]; such low friction is due to orientation of the HCP phase in a favourable direction [22]. However, under low contact pressure, stellite produces high levels of friction [23]. This is why the coatings were examined at three loads $(5,10$ and $15 \mathrm{~N})$ for ball-on-disc tests. CGS stellite- 6 coatings rubbed with WC-6Co exhibited a wear rate of $8.22 \times 10^{-6} \pm 1.46 \times 10^{-6}, 9.57 \times 10^{-6} \pm 1.56 \times 10^{-6}$ and $6.04 \times 10^{-6} \pm 1.06 \times 10^{-6}$ $\mathrm{mm}^{3} / \mathrm{Nm}$ respectively. Slight differences are appreciated when considering the standard deviation of these values; however, our findings show that the higher the load applied, the smaller the wear rate. Such results they might be associated with the highest oxidation. Persson et al. [22]tested laser-processed stellite-21 alloy under oxygen-free and air environments and found an increased wear rate for the alloys in the former conditions. In [7], the pin-on-disc behaviors of stellite- 6 and stellite- 21 were compared using various pin materials and testing conditions. A volume decrease in the order of $9.0 \pm 0.5 \mathrm{~mm}^{3}$ was observed compared to $0.46 \pm 0.03 \mathrm{~mm}^{3}$ for stellite- 6 and stellite- 21 respectively.

It is generally difficult to clearly establish the dominant sliding wear mechanism; given that this wear is known to occur mainly by adhesion [24,25], delamination [26] and/or fretting [27]; in the present case, the possibility of phase transformation role had also to be taken into consideration. The wear track of the loads examined showed thin chips with a scaled-like appearance (Figure 8) consisting of oxidized metal, as verified by EDS (Figure 9); this finding is indicative of a fretting mechanism, which is here understood as the low amplitude oscillation within the anular contact area where some tangential motion is given leading to small sliding displacements along the sliding direction; in the present case, this is observed as the formation and fracture of the oxide scale during rotating sliding wear. The discontinuity in oxide formation may explain the variations in the FCs plotted in figure 10 .

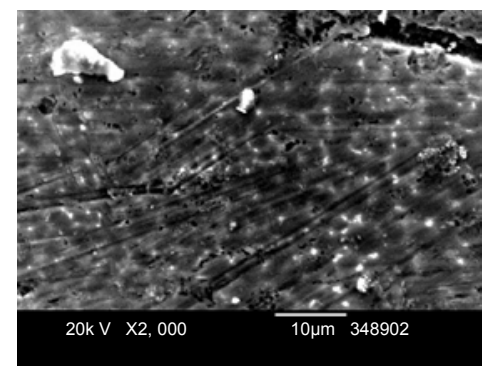

Figure 6: SEM micrograph of the worn surface of the stellite coating

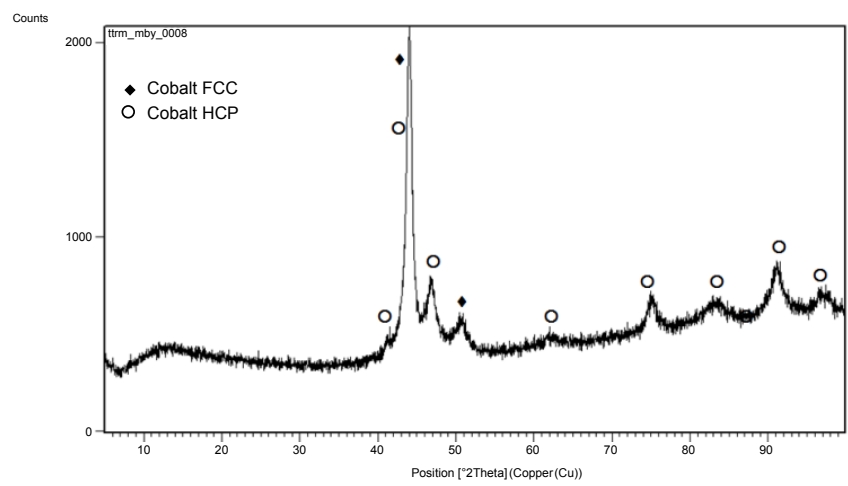

Figure 7: X-ray diffraction of the abraded zone.
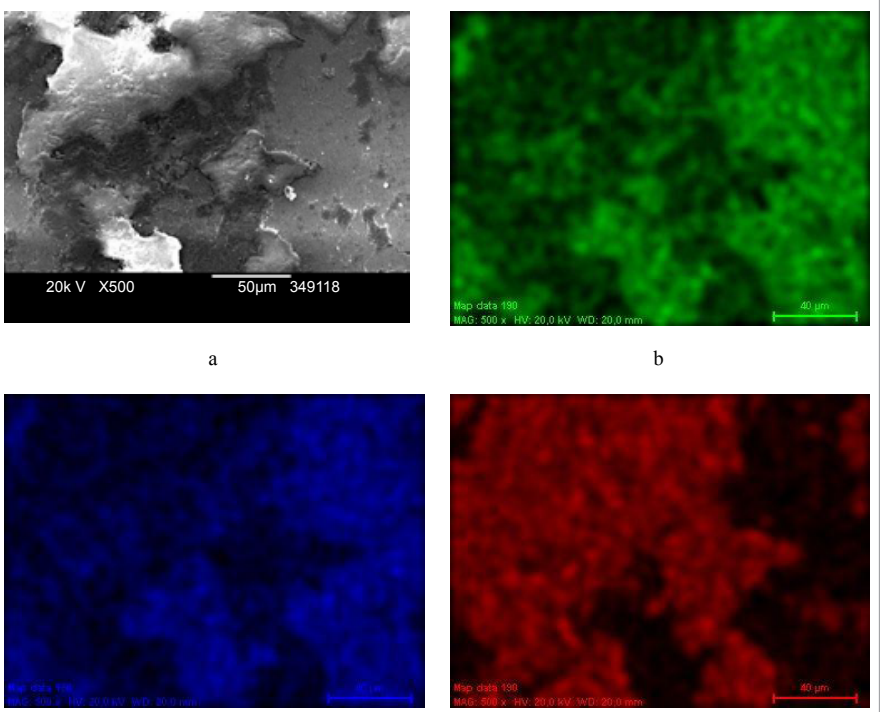

$\mathrm{c}$

d

Figure 8: (a) SEM micrograph of the wear track at $5 \mathrm{~N}$ and, mapping of (b) Co, (c) $\mathrm{Cr}$ and (d) $\mathrm{O}$

For other materials, the presence of oxidation in the wear track has also been reported to be responsible for lowering the FC when loads are increased $[28,29]$. Given that in the present case the HCP phase was detected by XRD in both the as-polished state before the test and after the test without any sign of preferred orientation, we propose that the decrease in the FC occurs as a result of the oxide scale. This notion contrasts with the results described by Persson et al. [23] who concluded that the friction level is controlled by the shearing of HCP 


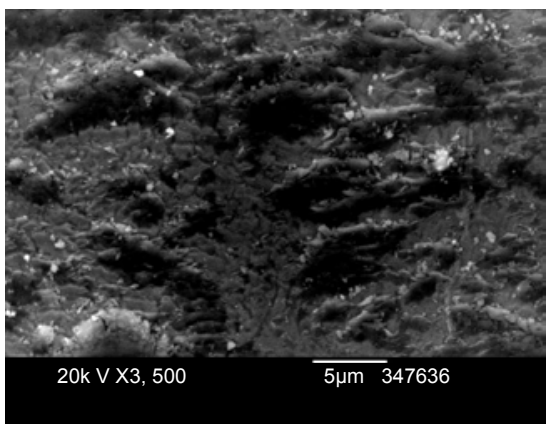

Figure 9: SEM micrograph of the scaled-like oxide chips

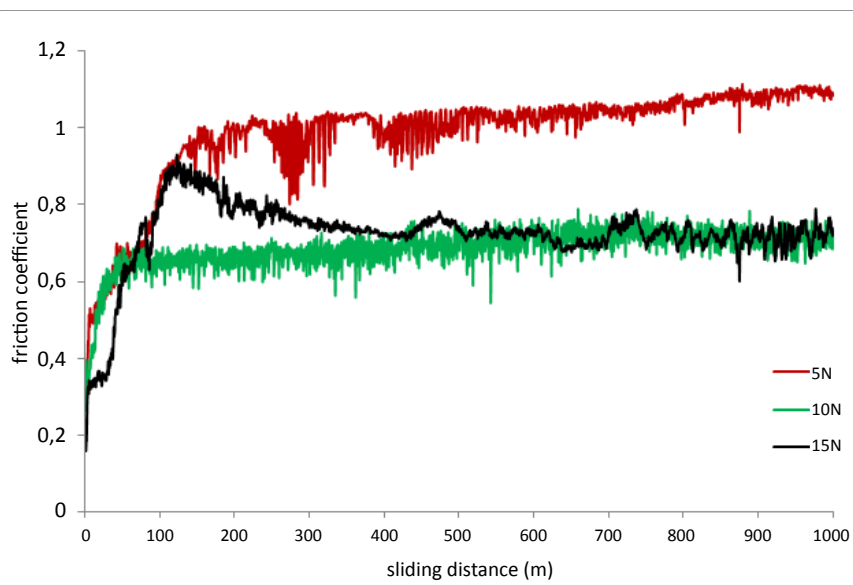

Figure 10: Evolution of the friction coefficient along the sliding distance for the loads tested.

$\left\{\begin{array}{llll}0 & 0 & 0 & 1\end{array}\right\}$ planes rather than by the presence of an oxide layer. This difference could be attributed to the fact that those authors worked at much higher loads, increasing from 200 to 2200 N. Much lower FCs would therefore be expected with the CGS coatings working at higher loads. Moreover, Inman et al. [30] built many wear maps for stellite-6 at various temperatures to predict the sliding mechanism and indicated the favourable conditions for the formation of low friction continuous "glaze" layers, i.e those formed in mild wear. By keeping the load at a fixed value of $7 \mathrm{~N}$, those authors gave more importance to oxide formation. Therefore, it could be concluded that in the regime of low loads, the friction level is controlled by the oxide scale whereas the HCP orientation might control this variable at high loads.

\section{Conclusions}

The major results of this study can be summarized as follows:

1. CGS deposits of stellite-6 produced with optimized spraying parameters show almost no porosity. By using the extreme conditions of the spraying system, very little particle deformation is observed, thus preserving their initial spherical shape.

2. Close examination by transmission electron microscopy reveals that under the high strain rates typical of CGS technology, twinning rather than slip or martensitic phase transformation is the dominant mechanism behind stellite alloy deformation.

3. The tribological study allows us to conclude that abrasive wear occurs by microcutting and microploughing, with wear rates in the order of $1.88 \times 10^{-4} \mathrm{~mm}^{3} / \mathrm{Nm}$, whereas dry sliding wear takes place by fretting. Oxidation is caused by local heating while friction seems to play a more relevant role than shearing of HCP planes under the conditions tested; the appearance of the HCP phase, however, is thought to be more important in the abrasive test.

\section{Acknowledgements}

The authors thank the Generalitat de Catalunya -project 2009SGR00310 and the CDTI-IDI-20090511 project carried out with JC-Fabrica de Valvulas. NCinca acknowledges the University of Barcelona for the award of a BDR postdoctoral grant.

\section{References}

1. Heimann RB, Lehmann HD (2008) Recently Patented Work on Thermally Sprayed Coatings for Protection Against Wear and Corrosion of Engineered Structures. Recent Patents on Materials Science 1: 41-55.

2. Vuoristo P, TuominenJ, Nurminen J (2005) Laser coating and thermal spraying - process basics and coating properties, Central Ostrobotnian Technology Centre, Finland.

3. Champagne VK (2007) The Cold Spray Materials Deposition Process: Fundamentals and Applications. Woodhead Pub Limited, UK.

4. Bunting BW, DebiccariA, Vargas C, KinstlerMD,Anderson DW(2009) Corrosion protective coating through cold spray.Patent number 20090011123

5. Yiping H,Murali M, Federico R (2006) Cold Gas-Dynamic Spraying of Wear Resistant Alloys on Turbine Blades. Patent number US 2005/0220995.

6. Schmidt T, Assadi H, Gartner F, Richter H, Stoltenhoff T, et al. (2009) From Particle Acceleration to Impact and Bonding in Cold Spraying. J Therm Spray Techn 18: 794-808.

7. http://dissertations.ub.rug.nl/FILES/faculties/science/1996/j.I.de.mol.van otterlo/c5.pdf

8. Christian JW (1975) The Theory of Transformations in Metals and Alloys: Equilibrium and general kinetic theory. Pergamon Press, UK.

9. Guilemany JM,Cinca N, Fernández J, Sampath S (2008) Erosion, Abrasive and Friction Wear Behavior of Iron Aluminide Coatings Sprayed by HVOF. J Therm Spray Techn 17: 762-773

10. Cinca N, Guilemany JM (2012) Structural and properties characterization of stellite coatings obtained by cold gas spraying. Surf Coat Tech.

11. Guilemany JM, Nin J, Miguel JR (2005) Stellite 6 coatings obtained by HVOF using different fuel gases. Thermal Spray 2005: Thermal Spray connects: 1225-1230.

12. Meyers MA, Benson DJ, Vohringer O, Kad BK, Xue Q, et al. (2002) Constitutive description of dynamic deformation: physically-based mechanisms. Mat SciEng A 322: 194-216.

13. Remy L (1978) Kinetics of f.c.c. deformation twinning and its relationship to stress-strain behaviour. ActaMetallurgica26: 443-451.

14. Korner A,Karnthaler HP (1983) Weak-beam study of glide dislocations in h.c.p. cobalt. Philos Mag A 48: 469-477.

15. http://dissertations.ub.rug.nl/FILES/faculties/science/1996/j.I.de.mol.van otterlo/c4.pdf

16. Borchers C, Gartner F, Stoltenhoff T, Kreye H (2004) Microstructural bonding features of cold sprayed face centered cubic metals. J ApplPhys 96: 42884292.

17. Wu X, Tao N, Hong Y, Liu G, Xu B, et al. (2005) Strain-induced grain refinement of cobalt during surface mechanical attrition treatment. Acta Mater 53: 681-691.

18. Archard JF, Hirst W (1956) The Wear of Metals under Unlubricated Conditions Proc R SocLondA 236: 397-410.

19. deMol van Otterloo JL, De HossonJThM (1997) Microstructure and Abrasive Wear of Cobalt-Based Laser Coatings. Scripta Mater 36: 239-245.

20. Zhao R, Barber GC, Wang YS, Larson JE (1997) Wear Mechanism Analysis of Engine Exhaust Valve Seats with a Laboratory Simulator. Tribol T 40: 209-218.

21. Chang SS, Wu HC, Chen C (2008) Impact Wear Resistance of Stellite 6 
Citation: Cinca N, Guilemany JM (2013) Cold Gas Sprayed Stellite-6 Coatings andtheir Wear Resistance. J Material Sci Eng 2: 122. doi:10.4172/21690022.1000122

Page 6 of 6

Hardfaced Valve Seats with Laser Cladding. Mater Manuf Process 23: 708713

22. Persson DHE, Jacobson S, Hogmark S (2003) The influence of phase transformations and oxidation on the galling resistance and low friction behaviour of a laser processed Co-based alloy. Wear 254: 1134-1140.

23. Persson DHE (2003) Laser processed low friction surfaces. Uppsala University Sweden.

24. Bowden FP, Tabor D (2001) The Friction and Lubrication of Solids. Oxford University Press UK.

25. Archard JF (1953) Contact and Rubbing of Flat Surfaces. J AppIPhys 24: 981 988.
26. Suh NP (1977) An overview of the delamination theory of wear. Wear 44: 1-16. 27. Waterhouse RB (1984) Fretting wear. Wear 100: 107-118.

28. Bin-shi X, Zi-xin Z, Wei Z, Shi-ning M (2004) The Microstructure and High Temperature Sliding Wear Behavior of Fe-Al Coating Produced by High Velocity Arc Spraying. Thermal Spray 2004: Advances in Technology and Applications (ASM International) 1052-1055.

29. Xu B, Zhu Z, Ma S, Zhang W, Liu W (2004) Sliding wear behavior of Fe-Al and $\mathrm{Fe}-\mathrm{Al} / \mathrm{WC}$ coatings prepared by high velocity arc spraying. Wear 257: 1089 1095.

30. Inman IA, Rose SR, Datta PK (2006) Studies of high temperature sliding wear of metallic dissimilar interfaces II: Incoloy MA956 versus Stellite 6. Tribollnt 39: 1361-1375. 